\title{
One-item susceptibility measure predicts waterpipe and little cigar/cigarillo uptake in a national sample of adolescents and young adults in the United States
}

\author{
Elizabeth N. Orlan', Tara L. Queen², Kurt M. Ribis/1,2, Erin L. Sutfin ${ }^{3}$
}

\begin{abstract}
INTRODUCTION Adolescents and young adults in the United States (US) are increasingly using non-cigarette tobacco products such as waterpipe (WP) and little cigars/cigarillos (LCC). One way to predict which non-user adolescents and young adults are most likely to use these products is through measuring their susceptibility or openness to using the products.

METHODS We conducted a national phone survey (baseline) and an internet survey (follow-up) of adolescents and young adults (ages 13-25 years), who, at baseline, had never used WP $(\mathrm{N}=1002)$ or LCC $(\mathrm{N}=990)$. At baseline, we measured susceptibility using a single item, asking participants whether they would try WP or LCC if their best friend offered it to them, and subsequently measured uptake at follow-up. We conducted multivariate regression analyses to determine whether product-specific susceptibility was a significant predictor of uptake at follow-up. RESULTS Participants who were susceptible and participants who had ever used another tobacco product had higher odds of using WP $(\mathrm{AOR}=3.5, \mathrm{AOR}=4.2)$ and $\mathrm{LCC}(\mathrm{AOR}=3.2, \mathrm{AOR}=5.3)$ at follow-up than those who were not susceptible to those products, and had not ever used tobacco products respectively, controlling for sociodemographic factors. The one-item measure had adequate sensitivity ( $\mathrm{WP}=51.4 \%, \mathrm{LCC}=40.2 \%$ ) and specificity $(\mathrm{WP}=84.9 \%, \mathrm{LCC}=87.9 \%$ ).

CONCLUSIONS Our national study of US adolescents and young adults shows that a one-item susceptibility measure at baseline was a significant predictor of WP and LCC uptake at follow-up, even after controlling for other predictors. Future research should assess the predictive validity of the one-item compared to the multi-item scale.
\end{abstract}

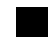
AFFILIATION
1 Department of Health Behavior, Gillings School of Global Public Health, University of North Carolina, Chapel Hill, United States 2 Lineberger Comprehensive Cancer Center, University of North Carolina, Chapel Hill, United States 3 Department of Social Sciences and Health Policy, Wake Forest School of Medicine, United States
CORRESPONDENCE TO Elizabeth N. Orlan. Department of Health Behavior Gillings School of Global Public Health University of North Carolina, Chapel Hill CBB 7440, Chapel Hill, NC 27599, United States. Email: eorlan@live.unc.edu ORCID ID: https://orcid.org/0000- 0002-3731-1078

\section{KEYWORDS}

adolescent, susceptibility, waterpipe smoking, cigar

Received: 8 February 2019

Revised: 2 April 2019

Accepted: 15 April 2019

\section{INTRODUCTION}

Cigarette smoking has declined among adolescents and young adults in recent years ${ }^{1}$; however, tobacco use, particularly non-cigarette tobacco use, remains a large public health problem in the United States (US). According to data from the National Youth Tobacco Survey, current cigarette smoking among high school students declined from $15.8 \%$ to $8 \%$ between 2011 and $2016^{1}$. The National Health Interview Survey showed that cigarette smoking among young adults (18-24 years old) had decreased from $24.4 \%$ to
$13.1 \%$ between 2005 and $2016^{2}$. Meanwhile, high school students' rates of current waterpipe (WP) use increased from 2011 to 2016; there was a significant, non-linear increase in current WP use among high school students from $4.1 \%$ to $4.8 \%{ }^{1}$. Among adults, the youngest group (18-24 years old) had the highest current use rates of WP compared to older age groups ${ }^{3}$. Cigars were the second most commonly used products among all high school students (7.7\%), and the most commonly used tobacco product among Black high school students $(9.5 \%)^{1,4}$. Among adults, 
the youngest age group used cigar products at the highest rates, compared to older groups ${ }^{1,3}$.

There are several health harms of waterpipe tobacco smoking and little cigar/cigarillo (LCG) use, most of which are similar to those of cigarette smoking, including respiratory illness and chronic obstructive pulmonary disease; cardiovascular disease; low birth-weight; and lung, oral, head, neck and esophageal cancers ${ }^{5-8}$. Waterpipe tobacco smoking emits high levels of carbon monoxide ${ }^{6}$ and the smoke contains known carcinogens such as polycyclic aromatic hydrocarbons and naphthylamines, some at higher levels than found in cigarettes ${ }^{9}$. Both WP and LCC contain nicotine, an addictive substance which leads to product dependence $^{6}$. These products are also often candy or fruit-flavored, which may attract adolescents and young adults for tobacco initiation ${ }^{10-14}$ and continued use thereafter ${ }^{6,15}$. Further, adolescent and young adult experimentation with WP has been associated with uptake of other tobacco products, including cigarettes $^{16-22}$.

Susceptibility is one known predictor of cigarette smoking experimentation ${ }^{23,24}$. Defined as how open a person is to future trial, susceptibility is typically measured using a well validated scale, including: whether a participant would use the product soon, within the next year, experiment in the future, and whether the participant would use the product if their best friend offered it to them ${ }^{23}$. The original multi-item scale, developed and validated for cigarette susceptibility by Pierce et al. ${ }^{23}$ has successfully predicted in several studies ${ }^{25-27}$ that one-third of adolescents will go on to become future cigarette smokers.

Researchers have adapted the Pierce et al. susceptibility scale to determine adolescent and young adult susceptibility to non-cigarette tobacco products $^{24,28-31}$. Lipkus et al. ${ }^{24}$ adapted the scale for use in a longitudinal study of waterpipe susceptibility among college students (young adults), predicting uptake at follow-up, while Trinidad et al..$^{30}$ assessed susceptibility rates and characteristics of susceptible youth in a cross-sectional nationally representative survey. Most recently, Cole et al. ${ }^{31}$ adapted a threeitem version of the Pierce et al. scale in a longitudinal sample of high school students in Ontario, Canada, testing the predictive validity of this susceptibility scale for several tobacco products, including LCC and $\mathrm{WP}^{31}$.

The three- and four-item (the latter including curiosity $)^{32}$ susceptibility scales can result in many items measuring this construct, especially when assessing a variety of tobacco products used in the US such as cigarettes, e-cigarettes, smokeless tobacco, and LCG. This is especially true if researchers are interested in measuring subsets of product classes, such as measuring separately large cigar, little cigar, and cigarillo susceptibility. In order to reduce participant burden, we measured susceptibility with one item, as the aim of this study is to assess the predictive validity of the one-item measure.

In selecting one item from the Pierce et al. scale, we considered previous research and theoretical models and selected the 'best friend' item. There is a vast, established literature explaining the role and influence of friends on adolescent risk behavior ${ }^{33-37}$. A study of London high school students found friends' use of tobacco products to be a significant predictor of waterpipe use ${ }^{38}$. Friends' smoking status and approval (i.e. social acceptability) of tobacco use are also often used as covariates in tobacco studies ${ }^{39}$. Further, another study of young adults from the US southeastern region found that greater frequency of waterpipe use was associated with friends' use, and that initial and current waterpipe use was associated with social activities ${ }^{40}$.

Additionally, in a longitudinal study of young adult waterpipe susceptibility, Lipkus et al. ${ }^{24}$ reported that the 'best friend' item was the most endorsed item. The 'best friend' item also differs from the other Pierce et al. susceptibility items ${ }^{32}$, which are: 1) 'Do you think in the future you might experiment with cigarettes?', 2) 'At any time during the next year, do you think you will smoke a cigarette? and 3) 'Have you ever been curious about smoking a cigarette?' The first two items seek to understand the participants' intention to use a product, and the third intends to understand environmental influences on one's interest in a product $^{32}$. Whereas the 'best friend' item seeks to measure 'efficacy expectations' or one's self-efficacy to refuse a cigarette if offered by a referent other ${ }^{32}$. Use of little cigars/cigarillos as a function of social interaction is less studied than waterpipe social 


\section{interactions.}

Given the number of tobacco products on the market, researchers often seek to assess use and susceptibility of each product, particularly among the populations that use them most. Adolescents and young adults have the highest use rates for non-cigarette tobacco products; further, many adolescents and young adults are using multiple tobacco products ${ }^{16,17}$. The ability to predict the future use of these products employing a less cumbersome measure could help researchers understand the characteristics of adolescents/young adults interested in using these products. Therefore, establishing a one-item susceptibility measure could reduce participant burden while still being a valid measure.

This study aims to: 1) Determine whether adolescent and young adult never users of WP and LCG who are susceptible to these products at baseline are more likely to use WP and LCC at follow-up than those who were not susceptible, controlling for other tobacco product use and sociodemographic variables; and 2) Assess the sensitivity and specificity of a one-item susceptibility measure for predicting a participant's uptake of WP/ LCC between baseline and follow-up.

\section{METHODS}

Two nationally representative baseline telephone surveys were conducted by the Carolina Survey Research Lab (CSRL) at the University of North Carolina between September 2014 and June 2015, the first of US adults aged 18 years and older, and the second of US adolescents aged 13-17 years. The national probability sample for the adult phone survey was recruited using two independent and nonoverlapping random digit dialing frames (both landline and cell phones), which resulted in 98\% coverage of all US adult households. Oversampling occurred in counties with higher smoking prevalence and higher poverty $^{41}$. A total of 5104 adults completed the survey, achieving a weighted response of $42 \%$ (AAPOR \#4) $)^{41}$. This study focuses on the young adult sub-sample, aged 18-25 years, of which 809 completed the survey. Additional information on the adult phone survey methods are provided elsewhere ${ }^{41-43}$

The adolescent telephone survey was conducted with a separate national probability sample of US adolescents aged 13-17 years (between November
2014 and June 2015) using three independent and non-overlapping samples, including two random digit-dialing frames (landline and cell phones) and a targeted sample, resulting in approximately $98 \%$ coverage of all US households. Similar to the adult survey, counties with higher smoking prevalence and poverty were oversampled. Parental consent was obtained from a parent/guardian, in addition, assent was obtained from the adolescent. In total, 1125 adolescents aged 13-17 years completed the survey (a $66 \%$ weighted response rate, AAPOR \# 4).

In October 2015, the CRSL conducted a followup survey, inviting 3612 participants from the phone survey sample, including 1768 adolescent and young adult participants aged 13-25 years. Data collection lasted three months and was mostly completed on the internet, but some surveys (19.3\%) were completed by mail among those who did not respond via email. Non-respondents were contacted up to three times by telephone reminder calls and mailings ${ }^{44}$. Among those aged 13-17 years (adolescents), there was an $84.4 \%$ (879) completion rate, among those aged 18-25 years there was a $59.6 \%$ (433) completion rate. Our total sample is shown in Figure 1. The sample included only

Figure 1. Sample flow chart, baseline and follow up.

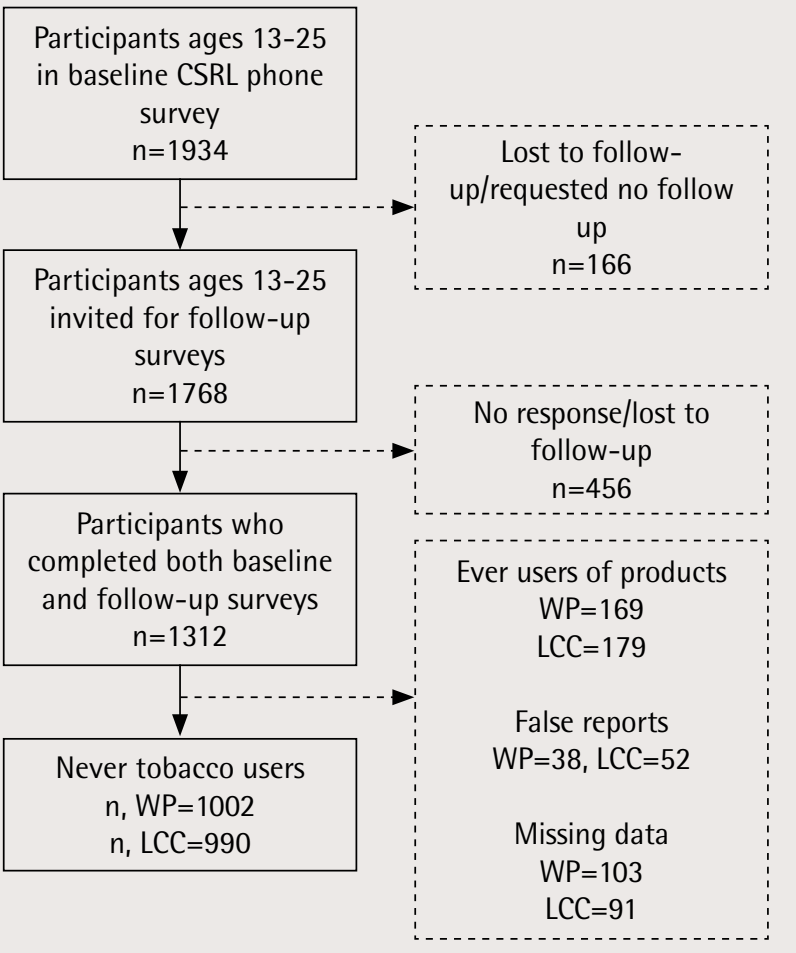


never users of WP and never users of LCC who had completed both the baseline and follow-up surveys, resulting in 1002 responses for WP and 990 responses for LCC. The institutional review board (IRB) at the University of North Carolina approved all study procedures. Informed consent for participation in the study was obtained verbally (for the phone survey) from respondents at the time of enrollment. For the adolescent population, both verbal assent from adolescent participants as well as verbal consent from the adolescents' parents or guardians were obtained.

\section{Measures}

Brief descriptions were given for each tobacco product to familiarize participants. Susceptibility was measured at baseline for waterpipe and little cigars/ cigarillos using the same item for each product ('If one of your best friends were to offer you [hookah, little cigars/cigarillos], would you use it? Would you say: definitely yes, probably yes, probably no, definitely no'). The item was subsequently coded dichotomously, with those who had responded 'definitely yes,' 'probably yes' or 'probably no,' as susceptible, and those who responded 'definitely no' as not susceptible, as categorized in previous work using this item ${ }^{23}$.

Ever (lifetime) use of LCC and WP were measured at baseline with the following item: 'Have you ever smoked [LCC/WP], even one or two puffs?' The same items were assessed at follow-up. We also measured participants' ever e-cigarette and cigarette use, as well as current smokeless tobacco use. Cigarette smoking was measured differently for adolescents and young adults. For adolescents' cigarette smoking, we used the same item as waterpipe and LCC shown above: 'Have you ever smoked a cigarette, even one or two puffs?' For young adults' cigarette smoking, we inferred ever cigarette use from two items: 1) 'Have you smoked at least 100 cigarettes in your entire life?' (Yes or No); and 2) 'Do you now smoke cigarettes every day, some days, or not at all?' Those who responded either 'yes' to the first question or indicated smoking 'every day' or 'some days' to the second question, were coded as 'ever users'. Tobacco products not involved in the primary analysis were grouped together as an 'ever use of any other tobacco product' variable in analyses (i.e. for WP analyses, ever use of LCC, cigarettes, e-cigarettes and smokeless tobacco were grouped into an 'ever tobacco use' category).

In addition, we assessed the following sociodemographics at baseline: mother's education (as a marker of socioeconomic status), gender, age, race, and ethnicity ${ }^{23,24,30,45}$. Age was measured continuously and coded by age category: adolescent (13-17 years) and young adult (18-25 years). Sex was measured as male or female. Race was measured categorically, using the measure: 'Which one of these groups would you say best represents your race?', with responses: White, Black or African American, American Indian or Alaska Native, Asian, Pacific Islander or other. It was subsequently coded dichotomously: White and all other races for analyses. Ethnicity ("Are you of Hispanic, Latino or Spanish origin?') was coded as Hispanic or non-Hispanic. Mother's education was measured categorically, ranging from no education to professional degrees, and coded as those who achieved less than or equal to a high school education versus some college or more. We used mother's education for both adolescents and young adults, as it is a proxy for socioeconomic status widely used in the tobacco literature ${ }^{16,46-49}$. Further, income data was missing in large subsets of our sample.

\section{Data analysis}

Descriptive statistics were calculated and multivariate, unweighted logistic regression analyses were conducted using SAS 9.4 (Cary, NC). The outcome of interest was product use at follow-up. To answer the first research question, stepwise regression models were used to determine whether the hypothesized variable (productspecific susceptibility) was a significant, explanatory predictor of WP and LCC uptake. Ever tobacco use was also included in the first model, because both variables have been significantly associated with subsequent initiation of tobacco products in other studies. We controlled forever use of other products to examine whether the association between susceptibility and future use was significant above and beyond history of trying other products ${ }^{16,30,50}$. In the second model, sociodemographic characteristics were added to the model as covariates, including sex, age group, ethnicity, race, and mother's education. 
To answer the second research question, we conducted sensitivity, specificity, positive predictive value (PPV) and negative predictive value (NPV) calculations. Sensitivity was defined as the per cent of those who reported using the product at followup who were susceptible at baseline. Specificity was defined as the per cent of those who reported not using the product at follow-up, of those who were not susceptible at baseline. PPV is the probability that a susceptible person would use the product at follow-up. NPV is the probability that a person who is self-classified as non-susceptible would not use the product at follow-up.

Several participants were removed from the sample (false reports) who responded at baseline that they had 'ever' used a product, and at follow-up reported that they had 'never' used a product (WP: 38; LCC: 52), as shown in Figure 1.

\section{RESULTS}

\section{Waterpipe (WP)}

The never users of WP sample (1002), as measured at baseline, consisted of $52.8 \%$ females and $47.2 \%$ males; had more adolescents (80.9\%) than young adults (19.1\%); and was predominantly White (78.5\%, 787) with $7.1 \%$ participants of Hispanic ethnicity. Over $22 \%$ of the respondents' mothers were high school graduates or had lower levels of education $(22.8 \%)$. Among never waterpipe users at baseline, $16.7 \%$ had ever used a tobacco product other than waterpipe and $17.7 \%$ were susceptible to waterpipe. At follow-up, 70 (7\%) of the waterpipe never users had initiated waterpipe, of which 36 (51.4\%) were susceptible to waterpipe at baseline. These and other characterizations of our sample are shown in Table 1.

Our first multivariate model showed that the hypothesized predictors, waterpipe-specific

Table 1. Unweighted sociodemographic and tobacco use characteristics at baseline by waterpipe and little cigar cigarillo use status at follow-up, 2014-2016 (WP, $\mathrm{N}=1002 ; \mathrm{LCC}, \mathrm{N}=990)$

\begin{tabular}{|c|c|c|c|c|c|c|}
\hline \multirow[b]{3}{*}{ Characteristics } & \multicolumn{3}{|c|}{ Waterpipe (WP) } & \multicolumn{3}{|c|}{ Little cigars cigarillos (LCC) } \\
\hline & $\begin{array}{l}\text { Full sample } \\
\text { at baseline } \\
\text { (N-1002) }\end{array}$ & $\begin{array}{l}\text { Users } \\
\text { at follow up } \\
\left.\text { (N-70; } 7.0^{\circ} \%\right)\end{array}$ & $\begin{array}{l}\text { Von-users } \\
\text { at follow up } \\
\text { (N 932; 93.0\%) }\end{array}$ & $\begin{array}{l}\text { Full sample } \\
\text { at baseline } \\
\text { (N-990) }\end{array}$ & $\begin{array}{l}\text { Users at } \\
\text { follow up } \\
\text { (N 97; 9.8\%) }\end{array}$ & $\begin{array}{l}\text { Non-users } \\
\text { at follow up } \\
\text { (N-893; } 90.2^{\circ} \text { ) }\end{array}$ \\
\hline & n $(\%)$ & n $(\%)$ & n $(\%)$ & n $(\%)$ & n $(\%)$ & n $(\%)$ \\
\hline \multicolumn{7}{|l|}{ Sex } \\
\hline Male & $473(47.2)$ & $27(38.6)$ & $446(47.8)$ & $452(45.7)$ & $48(49.5)$ & $404(45.2)$ \\
\hline Female & $529(52.8)$ & $43(61.4)$ & 486 (52.2) & 538 (54.3) & $49(50.5)$ & 489 (54.8) \\
\hline \multicolumn{7}{|l|}{ Age group } \\
\hline Adolescent & 811 (80.9) & $42(60.0)$ & $769(82.5)$ & $794(80.2)$ & $46(47.4)$ & 748 (83.8) \\
\hline Young adult & $191(19.1)$ & $28(40.0)$ & $163(17.5)$ & $196(19.8)$ & $51(52.6)$ & $145(16.2)$ \\
\hline \multicolumn{7}{|l|}{ Race } \\
\hline White & 787 (78.5) & $57(81.4)$ & $730(78.3)$ & 766 (77.4) & $68(70.1)$ & $698(78.2)$ \\
\hline Non-white & $215(21.5)$ & $13(18.6)$ & $202(21.7)$ & $224(22.6)$ & $29(29.9)$ & $195(21.8)$ \\
\hline \multicolumn{7}{|l|}{ Ethnicity } \\
\hline Hispanic & $71(7.1)$ & $7(10.0)$ & $64(6.9)$ & $77(7.8)$ & $10(10.3)$ & $67(7.5)$ \\
\hline Non-Hispanic & 931 (92.9) & $63(90.0)$ & $868(93.1)$ & $913(92.2)$ & $87(89.7)$ & $826(92.5)$ \\
\hline \multicolumn{7}{|c|}{ Mother's education } \\
\hline$\leq \mathrm{HS}$ graduate & $228(22.8)$ & $15(21.4)$ & 213 (22.9) & $223(22.5)$ & $25(25.8)$ & $198(22.2)$ \\
\hline$\geq$ Some college & $774(77.2)$ & $55(78.6)$ & $719(77.1)$ & 767 (77.5) & $72(74.2)$ & $695(77.8)$ \\
\hline \multicolumn{7}{|c|}{ Tobacco product use } \\
\hline Ever use & $167(16.7)$ & $37(52.9)$ & $130(14.0)$ & $156(15.8)$ & $53(54.6)$ & $103(11.5)$ \\
\hline Never use & 835 (83.3) & $33(47.1)$ & $802(86.0)$ & $834(84.2)$ & $44(45.4)$ & $790(88.5)$ \\
\hline \multicolumn{7}{|l|}{ Susceptible to WP } \\
\hline Yes & $177(17.7)$ & $36(51.4)$ & $141(15.1)$ & & & \\
\hline No & $825(82.3)$ & $34(48.6)$ & 791 (84.9) & & & \\
\hline \multicolumn{7}{|l|}{ Susceptible to LCC } \\
\hline Yes & & & & $147(14.8)$ & $39(40.2)$ & $108(12.1)$ \\
\hline No & & & & $843(85.2)$ & $58(59.8)$ & 785 (87.9) \\
\hline
\end{tabular}


susceptibility and ever use of another tobacco product, were both significant predictors of uptake $(\mathrm{OR}=3.5,95 \%$ CI: $2.0-6.1 ; \mathrm{OR}=4.4,95 \%$ CI: 2.5-7.6). We added the sociodemographic covariates into the second model to determine whether product-specific susceptibility remained a significant predictor. In the second multivariate model, adolescents and young adults who identified as susceptible to waterpipe at baseline had 3.5 times the odds of using waterpipe at follow-up compared to those who were not susceptible, controlling for sociodemographic factors $(\mathrm{AOR}=3.5,95 \% \mathrm{CI}: 2.0-$ 6.0). Adolescents and young adults who were ever users of another tobacco product at baseline had 4.2 times the odds of using waterpipe at follow-up compared to those who were not ever tobacco users, controlling for sociodemographic factors $(\mathrm{AOR}=4.2$, 95\% CI: 2.4-7.5). Those in the young adult age group, compared to adolescents, had 2.5 times the odds of waterpipe initiation at follow-up $(\mathrm{AOR}=2.5$, 95\% CI:1.4-4.5). The results of these models are shown in Table 2.

Table 2. Multivariate models depicting predictors of waterpipe tobacco (WP) and little cigar/cigarillo (LCC) initiation among never users of WP/LCC at baseline, 2014-2016

\begin{tabular}{|c|c|c|c|c|}
\hline \multirow[b]{3}{*}{ Characteristics } & \multicolumn{2}{|c|}{ WP initiation ( $\mathrm{N}=1002)$} & \multicolumn{2}{|c|}{ LCC initiation ( $\mathrm{V}=990)$} \\
\hline & Model 1 & Model 2 & Model 1 & Vodel 2 \\
\hline & $\operatorname{AOR}\left(95^{\circ} \% \mathrm{CI}\right)$ & $\operatorname{AOR}(95 \% \mathrm{CI})$ & $\operatorname{AOR}\left(95^{\circ} \% \mathrm{CI}\right)$ & $\operatorname{AOR}\left(95^{\circ} \% \mathrm{CI}\right)$ \\
\hline Female gender & -- & $1.7(1.0-2.9)$ & -- & $0.7(0.4-1.1)$ \\
\hline Young adult age group & -- & $2.5(1.4-4.5)^{*}$ & -- & $4.5(2.7-7.6)^{*}$ \\
\hline Race: Non-White & -- & $0.7(0.4-1.4)$ & -- & $1.3(0.7-2.2)$ \\
\hline Hispanic ethnicity & -- & $1.5(0.6-3.7)$ & -- & $0.9(0.4-1.9)$ \\
\hline Mother's ed. $\geq$ Some college & -- & $1.9(1.0-3.7)$ & -- & $1.4(0.8-2.5)$ \\
\hline Ever tobacco product use & $4.4(2.5-7.6)^{*}$ & $4.2(2.4-7.5)^{*}$ & $6.8(4.2-10.8)^{*}$ & $5.3(3.2-8.8)^{*}$ \\
\hline Susceptible to product & $3.5(2.0-6.1)^{*}$ & $3.5(2.0-6.0)^{*}$ & $2.8(1.7-4.6)^{*}$ & $3.2(1.9-5.4)^{*}$ \\
\hline
\end{tabular}

*Significant predictor. AOR: adjusted odds ratio.

\section{Little cigars and cigarillos (LCC)}

The never users of LCG sample (990) consisted of $54.3 \%$ females and $45.6 \%$ males. There were more adolescents $(80.2 \%)$ than young adults $(19.8 \%)$. The sample was predominantly White $(77.4 \%)$ and included $7.8 \%$ people of Hispanic ethnicity. About twenty-two per cent $(22.5 \%)$ of the respondents' mothers had education levels that were less than or equivalent to a high school degree. Among never LCC users at baseline, $15.8 \%$ had ever used a tobacco product other than LCC and $14.8 \%$ were classified as susceptible to using LCC. At follow-up, 97 (9.8\%) of those never users at baseline became users of LCC, of which $39(40.2 \%)$ were susceptible at baseline. These results are shown in Table 1.

Our first multivariate model for LCC showed that the hypothesized predictor, LCC-specific susceptibility was a significant predictor of uptake ( $\mathrm{OR}=2.8,95 \%$ CI: 1.7-4.6) even after controlling for other tobacco product use ( $\mathrm{OR}=6.8,95 \%$ CI: $4.2-$ $10.8)$. We also included sociodemographic covariates in the second model for LCG. In the second multivariate model, adolescents and young adults who identified as susceptible to LCC at baseline had 3.2 times the odds of using LCC at followup compared to those who were not susceptible, controlling for sociodemographic factors (AOR= 3.2, 95\% CI: 1.9-5.4). Adolescents and young adults who were ever users of another tobacco product at baseline had 5.3 times the odds of using LCC at follow-up compared to those who were not ever tobacco users, controlling for sociodemographic factors $(A O R=5.3,95 \%$ CI: $3.2-8.8)$. Those in the young adult age group, compared to adolescents, had 4.5 times the odds of LCC initiation at follow-up (AOR=4.5, 95\% CI: 2.7-7.6) (Table 2).

\section{Classification accuracy}

We tested the sensitivity, specificity, positive predictive value and negative predictive value for using this one-item measure to predict product uptake among sub-groups. There was a $7 \%$ uptake rate for waterpipe among never users at baseline. However, among susceptible individuals, $51.4 \%$ initiated WP 
(sensitivity). Among non-susceptibles $84.9 \%$ did not initiate WP (specificity) (Table 3 ).

Table 3. Sensitivity, specificity, positive predictive value (PPV) and negative predicted value (NPV) of the one-item susceptibility measure for waterpipe tobacco (WP) and little cigars cigarillos (LCC)

$\begin{array}{lcc} & \text { IVP } & \text { LCC } \\ \text { Property } & \%\left(95^{\circ} \circ \mathrm{CI}\right) & \%\left(95^{\circ} \mathrm{CII}\right) \\ \text { Sensitivity } & 51.4(39.2-63.6) & 40.2(30.4-50.7) \\ \text { Specificity } & 84.9(82.4-87.1) & 87.9(85.6-90.0) \\ \text { PPV } & 20.3(14.7-27.0) & 26.5(19.6-34.4) \\ \text { NPV } & 95.9(94.3-97.1) & 93.1(91.2-94.7)\end{array}$

There was a $9.8 \%$ uptake rate for LCC among never users at baseline. However, among susceptible individuals, $40.2 \%$ initiated LCC ( sensitivity), while among non-susceptibles $87.9 \%$ did not initiate LCC (specificity) (Table 3).

Given the rare occurrence of LCC and WP use, ( $<10 \%$ for each product), these calculations suggest that this measure is an adequate predictor of those who are more likely to use the product at followup, and are similar to the values obtained in other cigarette susceptibility studies ${ }^{51}$.

\section{DISCUSSION}

This paper is the first longitudinal analysis of whether a one-item product-specific, susceptibility measure predicts uptake of WP and LCC at follow-up among never users at baseline. This susceptibility measure can be used in contexts where researchers either seek to measure susceptibility to multiple tobacco products but do not have the resources to use a multi-item scale for each product, or aim to reduce participant burden.

These findings, from a national sample of US adolescents and young adults, show that a oneitem susceptibility measure for WP and LCC use can predict future tobacco product initiation, even after controlling for sociodemographic factors and other tobacco product use. Our findings expand on previous findings in the WP and LCC susceptibility literature. Lipkus et al. ${ }^{24}$ measured susceptibility to waterpipe smoking and its association with waterpipe uptake among a cohort of 964 college students using a four-item susceptibility scale. Participants susceptible in 2012 were 2.5 times more likely to report having used waterpipe the subsequent year than non-susceptible participants, after controlling for other correlates including gender, cigarette use, other tobacco product use, drinking and sensation seeking ${ }^{24}$. Our study was able to predict a similar trend in use, with only one item, controlling for similar sociodemographic and tobacco use variables.

The research of Trinidad et al. ${ }^{30}$ showed patterns of susceptibility among never users of any tobacco product who were aged 12-17 years. This study found that the majority of single product users were categorized as susceptible to using additional tobacco products ${ }^{30}$, which led us to include tobacco product use history in our model. Among e-cigarette users, $71 \%$ were susceptible to waterpipe and $56 \%$ to cigars, which could explain the increased odds of ever users of another product being susceptible and ultimately using WP and/or $\mathrm{LCC}^{30}$. In our study, ever tobacco product use was a significant predictor for both WP and LCC uptake.

Cole et al. ${ }^{31}$ measured the predictive validity of the Pierce et al. three-item scale for cigarettes and non-cigarette tobacco products among a sample of high school students in Canada. They found that the sensitivity and specificity for the measure were still highest for cigarettes ${ }^{31}$. When comparing these values to those from our study, they show similar patterns, though our study measures participants' ever use of the product, whereas Cole et al. ${ }^{31}$ measured participants' current use of the product.

Cole et al. ${ }^{31}$ state that either 'all three measures or a single question from the construct' could be used in future studies to measure susceptibility. In their study (in 2018, following our survey), they recommend using a different one-item ("do you think in the future you might try smoking [WP/ LCC]?') to measure susceptibility among Canadian high school students. Future studies are needed to verify the best one-item for tobacco product susceptibility using a national US sample, and we will ensure we measure this construct in future studies given the best available measurement evidence.

Although the finding that those who have ever used another tobacco product (i.e. little cigar/ cigarillo, e-cigarette or cigarette) are more likely to use waterpipe is not novel ${ }^{22}$; it shows a continued trend of adolescents and young adults as polytobacco users. Further, adolescent and young adult 
behavior patterns are ever evolving, and therefore continuous tracking of these trends is important to prepare targeted prevention and cessation interventions.

Future research should assess whether susceptible never users remain never users, and whether ever users sustain product use or switch to different products, to better characterize behaviors over time. Future research might also assess reasons for interest in products and product use, as well as whether those reasons change over time.

The Food and Drug Administration (FDA) has the authority, as of August $2016^{52}$, to regulate WP and LCC, and may use these findings to be able to 'track' potential uptake among these priority risk groups. Further, the FDA has recently announced plans to ban flavored tobacco products, which includes a specific plan for LCC products ${ }^{53}$. Though this is likely to face legal challenges, understanding all factors that predict use of these products can help to inform the case to ban these flavors. These data can also inform trends in WP/LCC product use when policies go into effect on these products, further allowing researchers to track the impact of policy change on behavior.

\section{Limitations and strengths}

There are several limitations in this study. Because we did not use the four-item susceptibility scale ${ }^{23,32}$, we were unable to compare the performance of the one item compared to the full scale in our sample. However, the measure as used, does have predictive validity in our sample, as shown through the increased odds of use at follow-up among susceptible users and ever tobacco product users, and the results of sensitivity testing conducted. Additionally, we do not have further waves of data, which might have otherwise provided further insight on whether susceptibles at baseline, who ever used at followup continued use of these products. Further, both surveys were based on self-report measures. This limitation was evident in the data analysis process, where certain participants who were ever waterpipe users at baseline reported being never waterpipe users at follow-up (Figure 1). This 'mismatch' in the data may be a symptom of the self-report survey design, and may also be related to the fact that the modality of survey was different at baseline (telephone) than follow-up (mostly completed on the internet). These 'mismatch' respondents were not included in our analyses, decreasing our sample size. Another potential reason that inconsistent responses may have occurred was that the follow-up survey contained risk message experiments about tobacco products, perhaps indicating a potential social desirability bias among participants, which was not measured independently. However, our study did have several strengths including a national sample of youth and young adults and a prospective design.

\section{CONCLUSIONS}

This study showed that those who self-reported affirmatively to being susceptible (using a oneitem measure at baseline) were more likely to use those products at follow-up, compared to those who were not susceptible, controlling for other tobacco product use and sociodemographic variables. This work also showed that the one-item susceptibility measure provides adequate sensitivity and specificity for predicting a participant's uptake of these tobacco products in this sample of adolescents and young adults. Given these results, researchers may be able to use this one item to predict susceptibility in a sample of adolescents and young adults.

Future research should continue to assess how to best predict adolescent and young adult uptake of waterpipe, LCC, and other emerging tobacco products when using self-report surveys. Longitudinal survey data can help public health professionals understand tobacco use patterns among these vulnerable age groups, assess whether and how behaviors change across the lifespan, and help identify high-risk individuals for interventions. Use of other methodologies, including mixedmethods or qualitative approaches, can help to increase understanding of the factors that may lead an adolescent or young adult to try WP or LCC; for example, in which social situations, with which friends (i.e. best friends, acquaintances; ever users, current users, or never users), and which products (and flavors, if available) stimulate the most interest. These methods, beyond the quantitative data presented in this article, may help tobacco control researchers understand predictors of adolescents' and young adults' interest in experimenting with or using WP and LCC, and in what ways researchers 
and public health practitioners can intervene to reduce interest in tobacco product initiation. Further, creation of health communication campaigns and subsequent evaluations specific to susceptible users of LCC and WP, as allowed through FDA jurisdiction in the US, can aid in preventing the uptake of these products.

\section{REFERENCES}

1. Jamal A, Gentzke A, Hu S, et al. Tobacco Use Among Middle and High School Students-United States, 20112016. MMWR Morb Mortal Wkly Rep. 2017;66(23):567603. doi:10.15585/mmwr.mm6623a1

2. Jamal A, Phillips E, Gentzke AS, et al. Current Cigarette Smoking Among Adults-United States, 2016. MMWR Morb Mortal Wkly Rep. 2018;67(2):53. doi:10.15585/mmwr.mm6702a1

3. Phillips E, Wang TW, Husten CG, et al. Tobacco product use among adults—United States, 2015. MMWR Morbidity and mortality weekly report. 2017;66(44):1209. https:// www.cdc.gov/mmwr/volumes/66/wr/mm6644a2.htm. Accessed February 8th, 2019.

4. Wang TW, Gentzke A, Sharapova S, Cullen KA, Ambrose BK, Jamal A. Tobacco Product Use Among Middle and High School Students-United States, 2011-2017. MMWR Morb Mortal Wkly Rep. 2018;67(22):629-633. doi:10.15585/mmwr.mm6722a3

5. Montazeri Z, Nyiraneza C, El-Katerji H, Little J. Waterpipe smoking and cancer: systematic review and meta-analysis. Tob Control. 2016;26(1):92-97. doi:10.1136/tobaccocontrol-2015-052758

6. National Center for Chronic Disease Prevention and Health Promotion (US) Office on Smoking and Health. The Health Consequences of Smoking-50 Years of Progress: A Report of the Surgeon General. Atlanta (GA): Centers for Disease Control and Prevention (US); 2014. https://www.ncbi.nlm.nih.gov/pubmed/24455788. Accessed February 8, 2019.

7. Chang CM, Corey CG, Rostron BL, Apelberg BJ. Systematic review of cigar smoking and all cause and smoking related mortality. BMC Public Health. 2015;15(1):390. doi:10.1186/s12889-015-1617-5

8. Waziry R, Jawad M, Ballout RA, Al Akel M, Akl EA. The effects of waterpipe tobacco smoking on health outcomes: an updated systematic review and meta-analysis. Int J Epidemiol. 2017;46(1):32-43. doi:10.1093/ije/dyw021

9. Maziak W. The waterpipe: an emerging global risk for cancer. J Cancer Epidemiol. 2013;37(1):1-4. doi:10.1016/j.canep.2012.10.013

10. Sterling KL, Fryer CS, Fagan P. The most natural tobacco used: a qualitative investigation of young adult smokers' risk perceptions of flavored little cigars and cigarillos. Nicotine Tob Res. 2015;18(5):827-833. doi:10.1093/ntr/ntv151
11. Martinasek MP, McDermott RJ, Martini L. Waterpipe (hookah) tobacco smoking among youth. Curr Probl Pediatr Adolesc Health Care. 2011;41(2):34-57. doi:10.1016/j.cppeds.2010.10.001

12. Ambrose BK, Day HR, Rostron B, Conway KP, Borek N, Hyland A, Villanti AC. Flavored tobacco product use among US youth aged 12-17 years, 2013-2014. JAMA. 2015;314(17):1871-1873. doi:10.1001/jama.2015.13802

13. Corey CG, Ambrose BK, Apelberg BJ, King BA. Flavored tobacco product use among middle and high school students-United States, 2014. MMWR Morb Mortal Wkly Rep. 2015;64(38):1066-1070. doi:10.15585/mmwr.mm6438a2

14. Villanti AC, Johnson AL, Ambrose BK, et al. Flavored Tobacco Product Use in Youth and Adults: Findings From the First Wave of the PATH Study (20132014). Am J Prev Med. 2017;53(2):139-151. doi:10.1016/j.amepre.2017.01.026

15. Feirman SP, Lock D, Cohen JE, Holtgrave DR, Li T. Flavored tobacco products in the United States: a systematic review assessing use and attitudes. Nicotine Tob Res. 2015;18(5):739-749. doi:10.1093/ntr/ntv176

16. Soneji S, Sargent J, Tanski S. Multiple tobacco product use among US adolescents and young adults. Tob Control. 2016;25(2):174-180. doi:10.1136/tobaccocontrol-2014-051638

17. Watkins SL, Glantz SA, Chaffee BW. Association of noncigarette tobacco product use with future cigarette smoking among youth in the Population Assessment of Tobacco and Health (PATH) study, 2013-2015. JAMA Pediatr. 2018;172(2):181-187. doi:10.1001/jamapediatrics.2017.4173

18. Mzayek F, Khader Y, Eissenberg T, Al Ali R, Ward KD, Maziak W. Patterns of water-pipe and cigarette smoking initiation in schoolchildren: Irbid longitudinal smoking study. Nicotine Tob Res. 2011;14(4):448-454. doi:10.1093/ntr/ntr234

19. Jensen PD, Cortes R, Engholm G, Kremers S, Gislum M. Waterpipe use predicts progression to regular cigarette smoking among Danish youth. Subst Use Misuse. 2010;45(7-8):1245-1261. doi:10.3109/10826081003682909

20. Jaber R, Madhivanan P, Veledar E, Khader Y, Mzayek F, Maziak W. Waterpipe a gateway to cigarette smoking initiation among adolescents in Irbid, Jordan: a longitudinal study. Int J Tuberc Lung Dis. 2015;19(4):481-487. doi:10.5588/ijtld.14.0869

21. Hampson SE, Andrews JA, Severson HH, Barckley M. Prospective predictors of novel tobacco and nicotine product use in emerging adulthood. J Adolesc Health. 2015;57(2):186-191. doi:10.1016/j.jadohealth.2015.04.015

22. Richardson A, Williams V, Rath J, Villanti AC, Vallone D. The next generation of users: prevalence and longitudinal patterns of tobacco use among US young adults. Am J Public Health. 2014;104(8):1429-1436. 
doi:10.2105/ajph.2013.301802

23. Pierce JP, Choi WS, Gilpin EA, Farkas AJ, Merritt RK. Validation of susceptibility as a predictor of which adolescents take up smoking in the United States. Health Psychol. 1996;15(5):355-361. doi:10.1037//0278-6133.15.5.355

24. Lipkus IM, Reboussin BA, Wolfson M, Sutfin EL. Assessing and predicting susceptibility to waterpipe tobacco use among college students. Nicotine Tob Res. 2014;17(9):1120-1125. doi:10.1093/ntr/ntu336

25. Strong DR, Hartman SJ, Nodora J, et al. Predictive Validity of the Expanded Susceptibility to Smoke Index. Nicotine Tob Res. 2015;17(7):862-869. doi:10.1093/ntr/ntu254

26. Choi WS, Gilpin EA, Farkas AJ, Pierce JP. Determining the probability of future smoking among adolescents. Addiction. 2001;96(2):313-323. doi:10.1046/j.1360-0443.2001.96231315.x

27. Gritz ER, Prokhorov AV, Hudmon KS, et al. Predictors of susceptibility to smoking and ever smoking: a longitudinal study in a triethnic sample of adolescents. Nicotine Tob Res. 2003;5(4):493-506. doi:10.1080/14622200307242

28. Unger JB, Rohrbach LA, Howard-Pitney B, Ritt-Olson A, Mouttapa M. Peer influences and susceptibility to smoking among California adolescents. Subst Use Misuse. 2001;36(5):551-571. doi:10.1081/ja-100103560

29. Primack BA, Soneji S, Stoolmiller M, Fine MJ, Sargent JD. Progression to Traditional Cigarette Smoking After Electronic Cigarette Use Among US Adolescents and Young Adults. JAMA Pediatr. 2015;169(11):1018-1023. doi:10.1001/jamapediatrics.2015.1742

30. Trinidad DR, Pierce JP, Sargent JD, et al. Susceptibility to tobacco product use among youth in wave 1 of the population Assessment of tobacco and health (PATH) study. Prev Med. 2017;101:8-14. doi:10.1016/j.ypmed.2017.05.010

31. Cole AG, Kennedy RD, Chaurasia A, Leatherdale ST. Exploring the Predictive Validity of the Susceptibility to Smoking Construct for Tobacco Cigarettes, Alternative Tobacco Products, and E-Cigarettes. Nicotine Tob Res. 2017;21(3):323-330. doi:10.1093/ntr/ntx265

32. Pierce JP, Distefan JM, Kaplan RM, Gilpin EA. The role of curiosity in smoking initiation. Addict Behav. 2005;30(4):685-696. doi:10.1016/j.addbeh.2004.08.014

33. Maxwell KA. Friends: The role of peer influence across adolescent risk behaviors. J Youth Adolesc. 2002;31(4):267-277. doi:10.1023/a:1015493316865

34. Castrucci BC, Gerlach KK, Kaufman NJ, Orleans CT. The association among adolescents' tobacco use, their beliefs and attitudes, and friends' and parents' opinions of smoking. Matern Child Health J. 2002;6(3):159-167. doi:10.1023/A:1019774028526

35. Hundleby JD, Mercer GW. Family and friends as social environments and their relationship to young adolescents' use of alcohol, tobacco, and marijuana. J Marriage Fam. 1987:151-164. doi:10.2307/352679

36. Lundborg P. Having the wrong friends? Peer effects in adolescent substance use. J Health Econ. 2006;25(2):214233. doi:10.1016/j.jhealeco.2005.02.001

37. de Vries H, Engels R, Kremers S, Wetzels J, Mudde A. Parents' and friends' smoking status as predictors of smoking onset: findings from six European countries. Health Educ Res. 2003;18(5):627-636. doi:10.1093/her/cyg032

38. Jawad M, Wilson A, Lee JT, Jawad S, Hamilton FL, Millett C. Prevalence and predictors of water pipe and cigarette smoking among secondary school students in London. Nicotine Tob Res. 2013;15(12):2069-2075. doi:10.1093/ntr/ntt103

39. Sidani JE, Shensa A, Yabes J, Fertman C, Primack BA. Waterpipe tobacco use in college and non-college young adults in the USA. Fam Pract. 2018;36(2):103-109. doi:10.1093/fampra/cmy037

40. Ward KD, Eissenberg T, Gray JN, Srinivas V, Wilson N, Maziak W. Characteristics of US waterpipe users: a preliminary report. Nicotine Tob Res. 2007;9(12):13391346. doi:10.1080/14622200701705019

41. Boynton MH, Agans RP, Bowling JM, et al. Understanding how perceptions of tobacco constituents and the FDA relate to effective and credible tobacco risk messaging: A national phone survey of US adults, 2014-2015. BMC Public Health. 2016;16(1):516. doi:10.1186/s12889-016-3151-5

42. Brewer NT, Morgan JC, Baig SA, et al. Public understanding of cigarette smoke constituents: three US surveys. Tob Control. 2017;26(5):592-599. doi:10.1136/tobaccocontrol-2015-052897

43. Jeong M, Noar SM, Zhang D, et al. Public understanding of cigarette smoke chemicals: Longitudinal study of US adults and adolescents. Nicotine Tob Res. 2019. doi:10.1093/ntr/ntz035

44. Baig SA, Byron MJ, Lazard AJ, Brewer NT. "Organic," "natural," and "additive-free" cigarettes: Comparing the effects of advertising claims and disclaimers on perceptions of harm. Nicotine Tob Res. 2018;1:7. doi:10.1093/ntr/nty036

45. Biener L, Siegel M. Tobacco marketing and adolescent smoking: more support for a causal inference. Am J Public Health. 2000;90(3):407. doi:10.2105/ajph.90.3.407

46. King JL, Reboussin BA, Spangler J, Ross JC, Sutfin EL. Tobacco product use and mental health status among young adults. Addict Behav. 2018;77:67-72. doi:10.1016/j.addbeh.2017.09.012

47. Juon HS, Ensminger ME, Sydnor KD. A longitudinal study of developmental trajectories to young adult cigarette smoking. Drug Alcohol Depend. 2002;66(3):303-314. doi:10.1016/s0376-8716(02)00008-x

48. O'Loughlin JL, Dugas EN, O'Loughlin EK, Karp I, Sylvestre MP. Incidence and determinants of cigarette smoking initiation in young adults. J Adolesc Health. 2014;54(1):2632.e4. doi:10.1016/j.jadohealth.2013.07.009

49. Ennett ST, Bauman KE, Foshee VA, Pemberton M, 
Hicks KA. Parent-child communication about adolescent tobacco and alcohol use: What do parents say and does it affect youth behavior? J Marriage Fam. 2001;63(1):4862. doi:10.1111/j.1741-3737.2001.00048.x

50. Leventhal AM, Strong DR, Kirkpatrick MG, et al. Association of electronic cigarette use with initiation of combustible tobacco product smoking in early adolescence. JAMA. 2015;314(7):700-707. doi:10.1001/jama.2015.8950

51. Nodora J, Hartman SJ, Strong DR, et al. Curiosity predicts smoking experimentation independent of susceptibility in a US national sample. Addict Behav. 2014;39(12):16951700. doi:10.1016/j.addbeh.2014.06.002

52. Food and Drug Administration, HHS. Deeming Tobacco Products To Be Subject to the Federal Food, Drug, and Cosmetic Act, as Amended by the Family Smoking Prevention and Tobacco Control Act; Restrictions on the Sale and Distribution of Tobacco Products and Required Warning Statements for Tobacco Products. Final rule. Fed Regist. 2016;81(90):28973-9106. https://www.ncbi.nlm. nih.gov/pubmed/27192730. Accessed February 8, 2019.

53. Gottlieb S. Statement from FDA Commissioner Scott Gottlieb, M.D., on Proposed New Steps to Protect Youth by Preventing Access to Flavored Tobacco Products and Banning Menthol in Cigarettes. https://www.fda. gov/news-events/press-announcements/statement-fdacommissioner-scott-gottlieb-md-proposed-new-stepsprotect-youth-preventing-access. Published November 15, 2018. Accessed February 8, 2019.
CONFLICTS OF INTEREST

The authors declare that they have no competing interests, financial or otherwise, related to the current work. E.N. Orlan, T.L. Queen and E.L. Sutfin report grants from the National Cancer Institute and FDA Center for Tobacco Products, during the conduct of the study. K.M. Ribisl reports grants from National Cancer Institute and FDA Center for Tobacco Products, during the conduct of the study; and other from the US Government, outside the submitted work.

\section{FUNDING}

Research reported in this publication was supported by P50CA180907 from the National Cancer Institute and the FDA Center for Tobacco Products (CTP). The content is solely the responsibility of the authors and does not necessarily represent the official views of the NIH or the Food and Drug Administration.

PROVENANCE AND PEER REVIEW

Not commissioned; externally peer reviewed. 